\title{
Effective curricula for at-risk students in vocational education: a study of teachers' practice
}

\author{
G. M. Fix ${ }^{1^{*}} \mathbb{D}$, H. T. M. Ritzen², J. M. Pieters ${ }^{1}$ and W. A. J. M. Kuiper ${ }^{3}$
}

${ }^{*}$ Correspondence:
mfix@landstede.nl
${ }^{1}$ Faculty of Behavioral,
Management and Social
Science, University
of Twente, Drienerlolaan
5,7522 NB Enschede, The
Netherlands
Full list of author information
is available at the end of the
article

${ }^{*}$ Correspondence: mfix@landstede.n

Faculty of Behavioral,

Science, University

of Twente, Drienerlolaan

5, 7522 NB Enschede, The

Full list of author information article

\begin{abstract}
Background: This study focused upon a curriculum for at-risk students in vocational education aimed at enhancing students' motivation and engagement for learning. The study explored teachers' view on effective curricular characteristics and teachers' strategies to create positive learning experiences for students.
\end{abstract}

Methods: Qualitative research has been conducted regarding four curricula for at-risk students; data were collected and examined by means of 16 focus group interviews with teachers and analysis of relevant documents.

Results: Teachers pointed out the central position of the student, resulting in individual trajectories. Teachers used peer group dynamics, job orientation and sports as tool for student development. Teachers regarded themselves as coaches, as experts in sport activities and as group managers. For positive learning experiences two key curricular characteristics have been identified: (1) equality in the relationship between student and teacher, (2) a positive fit between the curriculum and the students.

Keywords: Curriculum, Students at risk, Teachers' role, Teachers' practice, Vocational education

\section{Introduction}

Students leaving school without a basic qualification has been a problem over the past few decades (Lamb et al. 2011). Leaving school without a diploma causes problems from a personal perspective, for example, in finding a job (Brekke 2014), and experiencing poor health (Oreopoulos 2007). Moreover, drop-outs frequently become involved in criminal activities (Webbink et al. 2012). In the Netherlands, early school leaving occurs in all types of education, but most frequently in secondary vocational education, especially in the initial years and during school transitions (Elffers 2011; Ministry of Education, Culture \& Science 2017). Therefore, schools for vocational education are encouraged by the government to develop policy measures to prevent school dropout. However, a hard core of approximately 22,000 students simply lacks the ability to achieve certification at the required level (Ministry of Education, Culture \& Science 2017). These students generally seem to be somewhat "immune" to the measures taken up till now. Most of them have a "multi-problem" background, mainly characterized by the low social-economic status of their families, inadequate language and mathematical

(c) The Author(s) 2019. This article is distributed under the terms of the Creative Commons Attribution 4.0 International License (http://creativecommons.org/licenses/by/4.0/), which permits unrestricted use, distribution, and reproduction in any medium, provided you give appropriate credit to the original author(s) and the source, provide a link to the Creative Commons license, and indicate if changes were made. 
proficiency, low self-esteem and greater than average involvement in peer-group criminality.

To achieve the policy measures set by the Dutch Ministry of Education, Culture \& Science, i.e. providing more students with a basic vocational qualification, innovative and effective approaches to tackle this problem must be researched, developed and implemented.

Teachers of secondary vocational educational institutions (VET) in four cities in the Netherlands are cooperating in developing a curriculum for at-risk students. The schools are part of a project called "Playing for Success 15-23", which was launched as an early school leaver (ESL)-programme for secondary vocational students aged 15-23 and inspired by the British "Playing for Success" concept (Sharp et al. 2007). The innovative characteristic of this curriculum is the cooperation with professional sports organizations, such as a professional soccer club. In this program, at-risk students are assigned to a 8-10 week curriculum enacted in a professional environment such as a soccer stadium or top sports arena. The goal of this cooperation is to motivate at-risk students and engage them in learning and on the other hand to develop learning opportunities especially tailored to the educational needs of these students. The aim of this study is to examine whether dropout prevention, now typically located in a regular 'bricks and mortar' school environment, can be extended to a soccer stadium or top sports arena and to examine whether a professional, appealing environment with well-known sportspeople and a curriculum with many "binding" learning experiences reinforces the success of the ESL-programme." We assume that teacher impact really matters (Hattie 2003; Timperley and Alton-Lee 2008) and therefore we focus on teachers' views on effective dropout prevention and teachers' pedagogical-didactical strategies for creating positive and motivating learning experiences for at-risk students.

\section{Theoretical framework}

\section{Students at risk or disengaged students}

In the past decades, much research has been conducted to understand the complex phenomenon of school drop-out, yielding a list of explanatory risk factors that are derived from comparison of student groups that have dropped out with groups that remained in school (Rumberger 1995, 2001). These risk factors influence students' behavior, beliefs and attitudes over a long time, ultimately leading to dropping out. Early school leaving is understood to be the final step in a process of disengagement that originates in early childhood, long before the moment the student decides to quit school (Finn 1989). Generally dropping-out is presented as a function of individual student risk factors (Lee and Burkham 2003), like, for example the statistical likelihood of dropping out. These factors are mostly seen as an aggregate and students with a sufficient number of the specified characteristics are ranked as 'high drop-out risk'. In recent studies, more attention has been paid to risk factors at the school level, rather than the level of the individual students. Lee and Burkham (2003) stated that dropping-out can also be explained by school-related factors that include school structure and academic school organization. Earlier research presented the benefits for at-risk students when they experience their schools as communities (Battistich et al. 1997) expressed by students' feelings of belonging, care for each other and value of every individual at their school. Teachers 
have been identified as the strongest school-related factor, in how they foster positive learning experiences and support students and build teacher-student relationships (De Witte and Cabus 2013; Elffers 2012; Schuchart 2013; Wentzel and Wigfield 2007) and good teacher-student relations are characterized as supportive (Pyle and Wexler 2012) and caring (Cassidy and Bates 2005; Newberry 2010). Positive teacher-student relationships have been determined to have a variety of beneficial effects, such as higher student engagement (Ryan and Patrick 2001), motivation (Ryan and Deci 2000) and academic achievement levels (Martin and Dowson 2009). Van Houtte and Demanet (2016) argued that positive expectations from teachers have a positive impact on at-risk students, while in the work of Pyle and Wexler (2012) teachers are positioned as advocates who 'can implement academic and behavioral support in a school climate' (p. 287). Rumberger (2001) suggested that positive teacher-student relationships aim at building up social capital in school context, which is positively related to students' connection with school (Cemalcilar and Gökșen 2014). Ryan and Deci (2000) argued that motivation is related to the social conditions in which students develop and function; besides competence and autonomy, they also distinguished relatedness as a basic psychological need for proactive and motivated behavior, emphasizing the importance of supportive relationships for positive learning experiences.

In our study, the concept of at-risk students is synonymous with disengaged students and being at risk is considered to be an outcome of a progressive and cumulative process of disengagement with school that presents as a negative attitude towards school (Appleton at al. 2008; Finn 1989). Students at risk can be seen as students who are present in the school system but experience (the start of) a negative spiral, expressed by unmotivated or disengaged behavior, truancy and inappropriate classroom behavior such as resistance and passivity (De Witte and Csillag 2014; Markussen et al. 2011; Rumberger 1995). The concept of students' engagement is often split into three components that have an interwoven character, addressing the cognitive, emotional and behavioral engagement of students (Appleton et al. 2008; Fredricks et al. 2004). Teachers have a strong influence on students' engagement (Ryan and Patrick 2001), for instance, by building up positive relationships, creating a positive classroom atmosphere and challenging students with relevant learning activities (De Witte et al. 2013).

\section{Curriculum for at-risk students}

A curriculum has the potential to be the framework containing incentives for a positive influence on students, allowing students to experience the value of the curriculum for their personal lives (Elffers et al. 2012; Fashola and Slavin 2009; Keller 2010; Waldrip et al. 2014). Teachers have the challenging task of operationalizing the curriculum and translating its goals to the world of the student, making the connection between curricular activities and students' needs (Thijs and Van den Akker 2009). Elffers et al. (2012) pointed out the importance of the curricular fit for students' engagement and particularly students' emotional engagement.

For this study the curricular spider's web (Fig. 1) of Van den Akker (2003) was used as theoretical framework which represents how a curriculum is not only composed of learning content, learning activity and curricular objectives, but also can include other components equally important for fulfilling the raison d'être of the curriculum, 


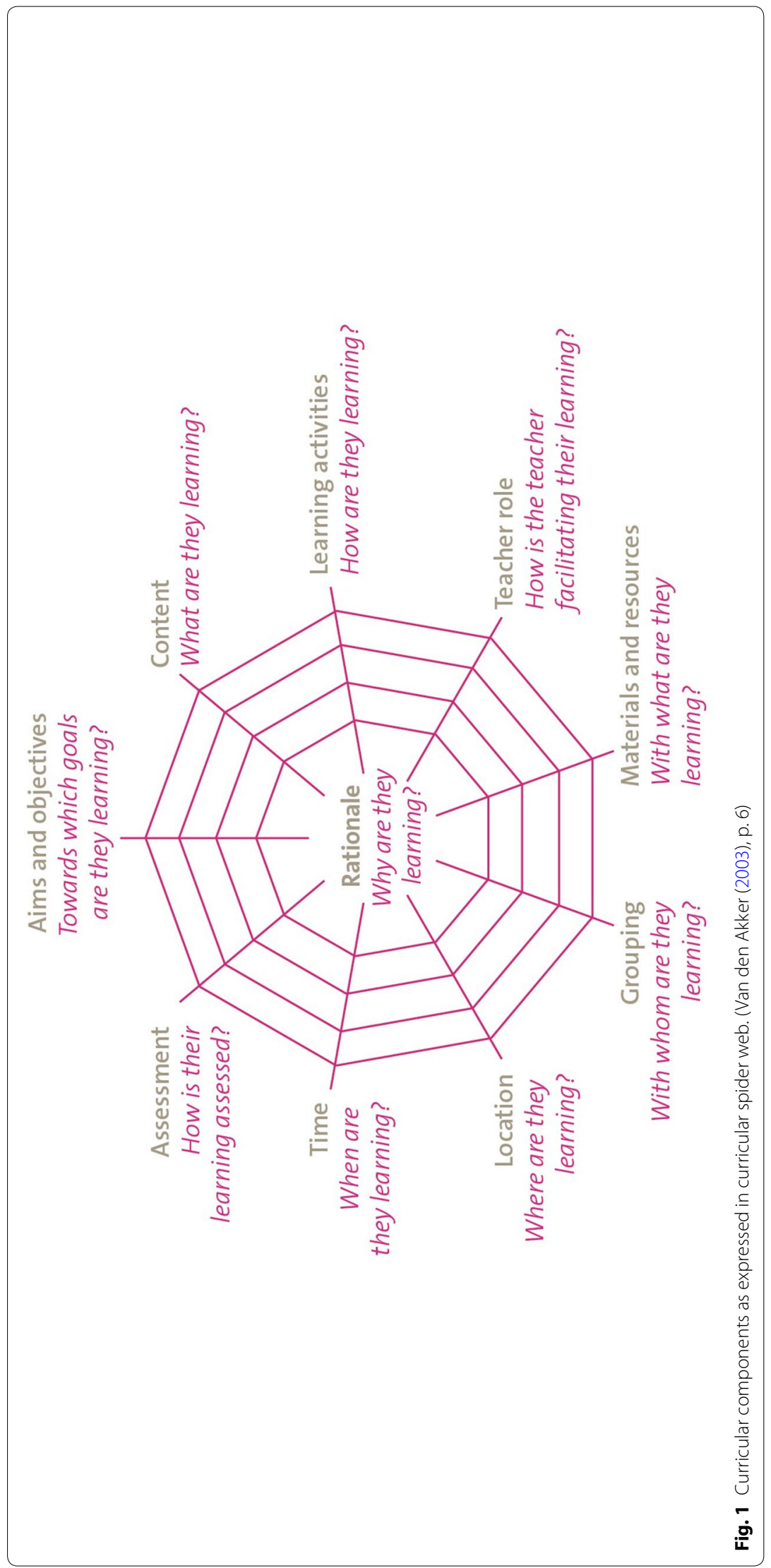


such as the role of the teacher, group composition, and physical environment. The present study focuses on curricula that were especially designed for students at risk. The work of Montgomery and Hirth (2011) provides insights for such a program addressing in the first place the importance on the curricular component of the teachers' role. According to Montgomery and Hirth (2011) teachers who enact a curriculum for at-risk students are identified as 'relationship builders', a role that cannot be performed by all teachers' (p. 259). Cassidy and Bates (2005) confirm that teachers of at-risk students have several roles including coach and mentor. The curricular goals (Fig. 1) must offer an opportunity for students to positively connect with school; the sense of belonging and engagement supports students' achievement and motivation (Elffers et al. 2012; Keller 2010). Curricular goals should include learning life skills, as at-risk students often lack generally accepted social skills, such as appropriate classroom behavior, showing respect towards others and being able to resolve conflicts before getting out of hand (Montgomery and Hirth 2011). The lack of these social competencies reduces their chance of having positive experiences at school, these students will receive more negative feedback and will have more conflicts with teachers and peers. In the work of Rumberger (2001) and Fashola and Slavin (2009), the curricular component of 'grouping' was discussed in connection with the student-teacher ratio. One of the most discussed approaches to enhancing students' engagement and achievement is reducing class size, which is proven to benefit students' learning (Smith and Glass 1980). Nonetheless, other researchers have doubted the class size impact (Hoxby 2000; Slavin 1989). The work of Sanders et al. (1997) and of Blatchford et al. (2011) draw attention to the mechanism that might explain why students are better supported in small classes, as they argue that teachers make the difference, rather than class size. In line with that Wentzel and Wigfield (2007) pointed out a central role for social relationships in interventions for at-risk students, they also proposed that 'more specification is needed to identify the precise way supportive teachers affects students' (p. 267). The work of Ryan (2000) focuses on the role of peers for students' motivation which also applies to the curricular component of 'grouping' in the curricular framework (Fig. 1), underlining that social relationships at school include not only teachers and students, but also peers.

For the present research four curricula are investigated aimed at re-engaging and motivating students at risk for learning. Teachers who enact the curricula are challenged to created positive and successful experiences at school for these students in order to engage them in learning. However, in teachers' practice, positive experiences and student success might be hampered by the behavioral patterns of these students, involving truancy, lack of discipline and motivation (De Witte and Csillag 2014; Markussen et al. 2011). Moreover, certain aspects of the school organization, such as the sheer size (in the Dutch context, VET school have an average of 7.350 students) and large classes, are not beneficial for building positive relationships between students and teachers and may be a threat for positive learning and success.

The present research is focused on teachers' perspectives regarding their experiences with the enacted curricula in order to identify key curriculum characteristics contributing the creation of positive learning experiences and success for student at risk. Based on the theoretical framework we formulate at the following research questions: 
Table 1 Overview of participants' characteristics

\begin{tabular}{lllll}
\hline School & Gender & Age (years) & Experience (years) & Background \\
\hline School A & & & \\
& Female & $>50$ & $>15$ & VET \\
& Male & $30-40$ & $5-15$ & Social work \\
& Male & $20-30$ & $<5$ & Social work \\
School B & Male & $30-40$ & $5-15$ & Social work \\
& & & & \\
& Female & $30-40$ & $<5$ & VET \\
& Female & $20-30$ & $<5$ & Social work \\
School C & Male & $20-30$ & $5-15$ & Job coach \\
& Female & $40-50$ & & SE \\
& & & $>15$ & VET \\
School D & Male & $>50$ & $5-15$ & SE \\
& Male & $30-40$ & & SE \\
& Male & $40-50$ & $>15$ & SE \\
& Female & $30-40$ & $>15$ & SE \\
& Female & $30-40$ & $5-15$ & SE \\
\hline
\end{tabular}

SE special education, VET Vocational Education Institute

1. From teachers' perspective and experiences, what are important and effective characteristics of the four executed curricula for at-risk students in vocational education?

2. Based on teachers' experiences, what are important conditions and strategies creating positive learning experiences for at-risk students in vocational education?

\section{Methods}

In order to answer the research questions, the present study provides an in-depth description of the characteristics of four curricula enacted at four different secondary vocational schools (each school enacted one curriculum). The curricula were described using multiple methods and two main data sources were used: written documents and focus group interviews. The collection of documents, usually on demand, has been a continuous process during the 18 months of data gathering. Documents were used to identify information about curricular characteristics, such as learning activities, pedagogical approaches and the target group of students. The document set covers a wide range: promotional materials, project plans, learning materials, school research reports and notes from meetings and evaluations. With the focus on teachers' practice in mind, only documents provided by teachers working with the curricula have been included. No further prescriptions were given regarding the documents, in order to collect as much documents as possible including different types of documents.

In addition to the documents data were gathered using semi-structured focus group interviews that were planned at every school. Groups were formed from teachers who enacted the curriculum at their school, resulting in three groups of four teachers and in one school a group of two teachers. The participating teachers had different backgrounds 
and varied in teaching experience; for an overview of participants' characteristics see Table 1.

The aim of the interviews was to identify the teachers' beliefs about effective curriculum characteristics for at-risk students based on their perceptions and experiences in practice. They were explicitly asked about personal experiences of success in practice and about personal beliefs related to the curriculum. For in-depth data collection teachers were followed 18 months and planning of the interviews was done in a ten to 12 week cycle taken into account the school year rhythm, including holidays and the curricular planning which was 8-10 weeks for a group of students. After 8-10 weeks teachers prepared themselves to start the curriculum again with another group of students and in between groups they were interviewed. Each interview took about an hour. In preparation for the interviews, teachers were informed about goal and content of the interview questions, and were asked to give permission for anonymous use of the information in the research. A total of sixteen interviews were held.

Selection of the schools hasn't been random; as mentioned before the participating schools were connected to the study through a nationwide project for students at risk in VET called 'Playing for Success 15-23' (15-23 referred to the age of participating students). They are situated in four different cities in the Netherlands being the only schools in the Dutch VET system that implemented these 8-10 week curricula aimed at at-risk students. During the research period, 6-8 different groups of students participated in the curricula at each school, according to the school timetable. Three curricula were stand-alone in which students participated full-time, not visiting other regular school curricular activities. One curriculum was supplementary to the regular school curriculum. The groups involved had a maximum size of 15 students and at least 2 teachers. As said above principal aim of the curricula was to enhance students' engagement for learning. All teachers who enacted the curriculum were involved in this study.

\section{Data analysis}

After collecting the data, the researcher went through a series of steps: preparing data for qualitative analysis, analyzing data and representing data. First all documents containing private or personal information were anonymized. A total of 37 documents were analyzed to obtain information about curricular characteristics (RQ1).

A total of 16 interviews were transcribed and anonymized. Data processing and analysis were performed based on the steps defined in the qualitative analysis guide of Leuven (QUAGOL) developed by Dierckx de Casterlé et al. (2012), which offers a comprehensive method to guide the process of qualitative data analysis. The QUAGOL method provides a coding scheme, for the actual coding process; the codes are not mutually exclusive, so that it was possible for data to be labeled with more than one code. Reliability of this analysis was checked first by discussing the code scheme with a colleague researcher experienced in qualitative research methods and with knowledge of the topic of at-risk students, yielding clarification of codes. After that data were coded by the head researcher and $10 \%$ of the data was coded independently by the second researcher. The comparison of their assigned codes yielded a Cohen's kappa of .910. All themes have been analyzed to identify the teachers' 
perspective on effective elements of the curriculum (RQ1). "Effective" was to be understood as "contributing positively to the main purpose of the curriculum", that is, to enhance students' school engagement. After that it was analyzed how, according to teachers, the curricular characteristics contributed to positive learning experiences (RQ2).

For verification the results were presented to the participating teachers and after this member check no adjustments were needed. The presentation of the results has been formatted according to the curricular framework of Van den Akker (2003).

\section{Results}

To answer research question one both interviews and documents provided insight into teachers' perspectives regarding the components of the curricular framework (Fig. 1). Teachers identified five curricular characteristics as important in their practice with at-risk students: (1) curricular goals; (2) curriculum content; (3) learning activities; (4) the role of the teacher and (5) the role of peer group. Teachers' perspectives on these curricular components are described below. For readability we first describe characteristics that were very similar at the four schools and secondly we describe characteristics that were specific for the four schools.

\section{Curricular goals and teachers' role}

The main aim or rationale of the curricula that was stated by teachers is the development of students' competencies. Mostly focused on life skills, such as making contact, the attitude towards others, handling feedback, communication, resolving arguments and offering help and support. Teachers considered development of students' competencies and life skills to stimulate social and emotional learning as an important condition for academic achievement. "If a student has arguments all day, he experiences low levels of well-being and his school achievement will be also low" and: "Before they can go back to school, they have to learn how to act appropriately in the school system".

Teachers working in this curriculum see their own role as being a coach and pointed out that coaching at-risk students means challenging students to make their own decisions and taking responsibility for these choices:"If you start telling them what to do, you better go home. That will not work. These students want to make their own decisions and they are tired of getting good advice". Furthermore, teachers emphasized the role of being a specialist at creating learning activities, specifically in sports:"most learning experiences arise all of a sudden, at that moment you have to make explicit for students what they can learn from it". Teachers also highlighted the transfer of learning outcomes achieved in sports activities to normal (school) life, for which teachers must know exactly what can be learned in sports and how this may benefit normal life. According to teachers, peers-interaction is one of the most meaningful aspects of the curriculum. Therefore teachers have to be experts in group management, and they must be able to re-direct negative peer group influences. Teachers agreed about the importance of the positive climate, but they also pointed out that this is a challenging task for them: " $A$ positive climate never arises without effort, these are kids who have negative experiences 
with peers and teachers, you have to show that things can change and we as teachers have to work hard for it". Teachers considered that for most regular teachers, additional training is necessary to be able to create a positive peer group atmosphere while working with these at- risk students.

In summary, teachers perceived the main aim of the curriculum as development of students' competencies and experienced their own role as being a coach, an expert on learning activities in sports and a skillful group manager. According to them, it was important to be able to switch easily between these roles.

\section{Curricular content, activities and peer group}

Teachers from the four schools implemented different learning activities and learning content in practice, as well as different roles of the peer group. These components and the teaching practices are described below for the four schools.

\section{School A}

Teachers at school A used the peer group to set up a positive environment; learning activities were aimed at meeting each other and having fun, sports activities were seen by teachers as optimal for teambuilding. Students' learning was focused on personal development by learning from each other's stories: "We have to build a safe environment and make sure that students can trust each other; then students will share their problems and learn from each other". In the peer group, students were prompted to help and correct one another, to share their (life) stories and recognize each other's problems, give advice or offer help. Learning goals at school A were focused around individual social competencies that students need at school: "If we want students to fit into the school system, they have to learn what kind of behavior is required in that system". Peer group dynamics were used to practice social behavior and to determine students' individual competencies regarding their social behavior: "Students often are surprised by the compliments they get from their peers, they have unrealistically negative self-images". Teachers at school A perceived that peers are indispensable in helping at-risk students to continue at school, especially when times get rough.

In summary, teachers at school A centered mainly on development of social competencies by creating a positive and stimulating learning environment with help of peers. They supposed that peer group involvement highly enhances students' engagement, as "Students feel they have to do this together".

\section{School B}

Teachers at school B focused on creating an inspiring environment for students: "Students often are tired and unmotivated when they start here, we try to create a new positive flow".

Teachers added exciting activities to the curriculum, such as sports activities yet unfamiliar to the students like mountain biking or free running; "We have a lot of sports activities in the curriculum, students are introduced to new sports skills and offered workshops by top sports athletes". In addition, teachers pointed out that the location, which was a well-known professional soccer stadium, was instrumental in creating an inspiring 
environment: "Students have to be away from the school building to get inspired, this stadium is the perfect location therefore".

Students' learning goals were aimed at the development of competencies connected to the labor market (such as presenting one-self, reflecting on one's own capabilities, handling feedback and communication skills): "We try to help students develop competencies they need to succeed in their future employment". This was operationalized through individual job orientation, by offering an internship in the sector of the student's personal interest combined with intensive job coaching, where teachers visited and coached the students frequently during their internship. Peer coaching was used to help develop students' employee competencies: "We challenge students to identify each other's competencies and match it to a job".

In summary, teachers a school B supposed that students can be supported by creating an inspiring and exciting learning environment, together with job orientation and development of students' employee competencies.

\section{School C}

Teachers at school $\mathrm{C}$ focused on sports activities as the key activity for students' development: "In sports you run into competencies you use in everyday life; it is important to find out how you react to difficult or even frightening tasks, you can learn from that". Teachers challenged students to develop competencies which are important for a positive attitude towards learning and positive classroom behavior such as asking for help, bringing up the motivation for difficult tasks, taking an interest in others, reflecting and creating strategies for problem-solving.

Development of students' competencies was interwoven with sports activities:" We choose sport activities that ask for more than just the sports skill, we ask for teamwork, creativity, problem-solving, persistence and communication". Students were coached and encouraged to extend lessons learned in sports to school situations (for example, when is persistence in normal school life important or how do you approach a difficult school task) in order to transfer the learning gain: "We see disengaged behavior in sports activities, this is exactly the kind of behavior that students also show at school; we ask them to reflect on it (...) they often are alarmed by their own attitude". Teachers at this school emphasized that supportive peers are important for a positive learning environment. Students can also help each other by providing feedback and asking questions. According to teachers, this peer feedback will enhance understanding of the student's own attitude and behavior and how this affects others: "We ask students to reflect on each other's actions. I think that feedback from peers is more important for them than my feedback".

In summary, teachers at school $\mathrm{C}$ focused on sports activities as instrumental for students' development and the transfer of learning gain in the sports context to school situations.

\section{School D}

Teachers at school D connected students' development to sports activities and the sports environment, in this case a top sports arena: "Sports and this sports location is our chosen instrument to reach the learning goals". In this curriculum, students' competencies were trained in sports activities:"If we know a student has problems with authority 
Table 2 Brief description of the curriculum per school

\begin{tabular}{|c|c|}
\hline & Short summary of the curriculum \\
\hline School A & $\begin{array}{l}\text { Target group consists of students who have dropped out of school, main aim of the curriculum was } \\
\text { to develop students' social competences and self-confidence in order to motivate them to go to } \\
\text { school and enhance engagement. Students were offered sports activities, (peer) coaching and job } \\
\text { orientation. If necessary, students also participated in health care or social care institutions }\end{array}$ \\
\hline School B & $\begin{array}{l}\text { Target group consists of students with study choice problems. Main aim of the curriculum was ori- } \\
\text { entation to the labour market and preparing students for working as employee. Students followed } \\
\text { internship with job coaching and were offered sports activities and lessons on employee skills } \\
\text { (such as self-discipline, providing feedback, solving conflicts and presenting one-self) }\end{array}$ \\
\hline School C & $\begin{array}{l}\text { Target group consists of students who lack basic school competences, such as persistence, planning } \\
\text { and asking questions. Students were offered sports activities, coaching and the general school } \\
\text { tasks in math and language. Main aim of the curriculum was to develop students'social com- } \\
\text { petences (showing respect, listening to each other, presenting one-self, asking for help) and to } \\
\text { motivate them for school }\end{array}$ \\
\hline School D & $\begin{array}{l}\text { Target group consists of students who have shown risk behaviour during their vocational track (such } \\
\text { as conflicts, loneliness, truancy or resistance towards school). Students were offered social skill } \\
\text { training (handling feedback, making contact, presenting one self and solving conflicts), sports } \\
\text { activities, and (individual) coaching. Main aim of the curriculum was decreasing risk behaviour and } \\
\text { enhancing positive feelings such as confidence and engagement with their vocational track }\end{array}$ \\
\hline
\end{tabular}

we organize sports activities to practice with that". According to teachers, the location was important owing to the variety in opportunities of sports activities and the stimulating sports climate that could be felt in the building (everyone was busy doing sports, including professional sports). Teachers in this curriculum supposed that learning in the sports context was most beneficial for social-emotional goals such as enhancing selfconfidence, decreasing behavioral problems and making friends. According to teachers, students need their peers to learn social skills: "Students need each other to achieve their goals. If you want to learn how to make friends, peers are essential and a compliment from a peer is more valued than a compliment from a teacher".

In summary, for the operationalization of students' development teachers of school D used sports as an instrument for learning and practicing social competencies.

Table 2 summarizes the differences between the schools, first addressing the target group, including drop outs, students with job orientation problems, lack of school competences and risk behavior. Although all curricula were aimed at development of students' competencies the prioritized competencies were slightly different caused by the differences in target group. The implemented learning activities were tailored to this target group, for example by focusing upon job orientation or providing skill training to students.

\section{Positive learning experiences}

Research question two focused on the teachers' practices during curriculum execution to create positive learning experiences for students. Teachers considered positive learning as successful reaching learning goals with students.

According to teachers, the most important condition for positive learning and student success was a supportive relationship with students and between students. Teachers emphasized the importance of equality in this relationship between teachers and students which was operationalized by teachers using a non-directive coaching style. According to the teachers, coaching in this way means in practice that teachers put a 
lot of effort into building a personal relationship with their students. Teachers asserted that this relationship requires for very personal interaction with students, including discussion of their personal feelings, behaviors and experiences, which they insert into the curriculum: "Yes, students know a lot about me, but that is necessary, I ask them to share difficulties with me, you would not do that with a total stranger, would you?". Teachers emphasized that it took a lot of courage to work on a basis of equality: "Sometimes it felt difficult to share my opinions with my students, I was scared I would lose my position as leader of this class". Teachers were convinced that this personal approach was the best (if not the only) way to achieve effective learning with at-risk students. In addition, they expressed that working in this personal way with students, calls for experienced and strong teachers with a lot of self-confidence. The coaching included evaluation of the learning process together with students, not assessing but reflecting about their learning process. In this regard, teachers addressed students' personal feelings and interests (for example, did the student experience success during a task and why). They also shared their own perspectives on the process (for example, what was the teachers' perspective on students' attitude towards peers during the task). Another strategy of teachers for creating a positive relationship was humor. Teachers frequently emphasized the importance of humor, making jokes, and having a natural, friendly and cheerful attitude towards students: "Students are often surprised that we laugh so much, they say that we are a little crazy". Teachers used these elements to build positive relations and to reduce students' stress levels in order to evoke happiness and feelings of joy: "We want to create a positive environment, so we laugh, we make fun and we make them feel happy, that costs no extra money, it is just a way of approaching". Humor enhances positive communicating and benefits engagement; according to the teachers, laughing and having fun was one of the most important ways to make students more open and accessible for a relationship.

In addition for positive peer interaction, teachers preferred students coming from different school levels, with different interests and experiences, because this variety contributed to the effectiveness of peer coaching and peer feedback. Students learned from listening to different points of view and have the opportunity to make new friends among unknown peers. According to the teachers, relationships with peers should have a positive and supportive character (for example, peer coaching can contain to solutions for a problem, sharing feelings and discussing difficult situations). Teachers emphasized that group size matters for effective peer feedback and peer coaching; they recommended a teacher to student ratio of $1: 8$, which is a relatively small class size comparing to regular vocational education. Teachers emphasized the importance of small groups for intensive and effective coaching in order to create positive peer group interaction: "This group was too large, I could not speak every student every day although that was highly necessary".

The second condition for positive learning experiences and student success was the match between students' needs and the curriculum. In this curriculum, teachers pursuit this match in several ways. First of all they aimed at the adaptation of curriculum goals, namely adapting content and activities to students' individual needs and interests, making the curriculum relevant for them and motivating: "We try to adapt in this curriculum to the need of the individual student as much as possible" In practice individual learning trajectories were applied, with individual learning goals and learning activities, resulting in differentiated learning outcomes for every student. Teachers explicitly encouraged 
students by formulating their learning goals, in terms of the competencies which must be developed: "We ask them what they think is the problem and how they want to solve that". These learning goals in turn were translated by the teachers into curricular activities regarding the questions, struggles or needs of the students. As described, sports activities were used in this curriculum to create new and inspiring learning experiences in which students engage because of fun and interest (for example, through unfamiliar sports as wall climbing, or a basketball clinic from a professional basketball player): "Students are exciting about the sports, they like it and for us it is an excellent way to challenge their persistence or teamwork skills". Another way of building a bridge between student and curriculum was the use of an interesting location, like a sports stadium or arena. Although all teachers agreed that the sports context was probably not the only option, they stated that this curriculum cannot as successfully be enacted in the school building. The location evokes interest in students and makes them curious, which is a prerequisite for engagement in the first place. As one teacher said, "They come for the stadium, but they stay for the curriculum and their peers". Moreover, the location reduces stress for students who have built up resistance towards school and teachers, and the first step in changing their disengaged attitude was to be out of the school building in a different, interesting context: "Students relax here because this is not school for them".

\section{Conclusion}

This study has been focused on teachers' educational practice with at-risk students in secondary vocational education. Our first question was aimed at teachers' perspectives regarding effective characteristics of a curriculum aimed at enhancing at-risk students' motivation and engagement for learning. Teachers identified five curricular characteristics as important in their practice with at-risk students: (1) curricular goals must be aimed at development of students' competencies; (2) the curricular content and (3) the learning activities must both tailored to the target group of students; (4) the role of the teacher was defined as being a coach of social skills, as an expert in the use of sports activities to develop students' competencies, and as a group manager, being able to create a positive peer group climate and: (5) supportive peer interaction.

The second research question addressed teachers' perspective on positive learning experiences for students. Teachers in this study emphasized the indispensable contribution of positive learning experiences on students' motivation for learning and defined positive learning as successful reaching learning goals. Two key curriculum characteristics for positive learning were mentioned: (1) equality in the relationship between student and teacher and between students, operationalized in practice by non-directive coaching, sharing personal stories and humor; and (2) a match between the curriculum and the students by the adaptation of learning activities, learning content and learning goals to students' individual needs, engaging students in goal-setting, attractive sports activities and a location outside the school building. 


\section{Discussion}

In this study, key characteristics of four curricula in secondary vocational education were explored based on teachers' practical experiences. The curricula were implemented for students who showed disengaged and unmotivated behavior and who were at risk of dropping out of the school system. Ryan and Deci (2000) proposed that students' development of self- motivation depends on the social contextual conditions. These authors postulated three psychological needs, which, when satisfied, yield enhancement of students' motivation (Ryan and Deci 2000): autonomy, competence and relatedness. It became clear that teachers in this program were aware of students' psychological needs, resulting, for example, in the application of an autonomous approach to goal setting, a focus on development of students' individual competencies and coaching as the teaching role. Teachers are aware of the fact that creating a positive relationship with students is necessary to satisfy students' psychological needs. Results also presented a strong emphasis in this curricula on social and emotional learning, valuing and respect for every individual and care for each other. This climate has similarities to the description of schools as communities (Battistich et al. 1997), with high levels of care for each other, sense of belonging and feelings of membership being identified as beneficial for motivation and social behavior.

According to Cassidy and Bates (2005), at-risk students require teachers who are a 'cross between a teacher and a counselor, a motivator, a mentor, a leader, all at the same time' (p. 83), underlining the complexity of teaching these students, which calls for well-prepared teachers characterized in the literature as teachers with high levels of engagement (Rumberger 2001) and high self-efficacy scores (Van Uden et al. 2013). In this study, teachers experienced their role primarily as being a coach, which to them implied an equal relationship between student and teachers. Prior research on the teacher's role emphasized the teacher as a supportive and caring coach or mentor (Cabus 2012; De Witte and Cabus 2013; Van der Steeg et al. 2012). Cassidy and Bates (2005) proposed that teachers should take a more personal role by sharing their lives with students, emphasizing that teaching at-risk students is, at first, a matter of building relationships. In the Dutch setting, teachers in secondary vocational education are primarily teachers who have a lot of professional experience in their field. We assume that working with at-risk students requires less emphasis on teachers' formal didactical skills (teaching as a profession), but more on the skills necessary to build relationships; it can be questioned whether teachers in secondary vocational education in the Dutch educational setting are aware of these differences and moreover, are capable of combining both types of skills.

Relatedness, in this study, was not restricted to relationships between teacher and student. Peer connection was also emphasized by teachers as important for building relatedness. In the framework of Van den Akker (2003), the component of 'grouping' involves peers; however, this component does not explicitly address the role peers have in the curriculum as related to other students. For example, teachers in this curriculum used peers for providing feedback. The literature provides evidence that peers are a strong factor in students' process of disconnection from school (Ryan 2000). Therefore, we suggest that in curriculum design for at-risk students careful consideration of the role of the peer group is necessary, as peers influence students a great deal, positively as well as 
negatively. According to our findings we are convinced that the curricular component of grouping (Van den Akker 2003) is for a positive group process in the peer group and teachers have to consider how to stimulate interactive group dynamics in the curriculum for example by learning activities that contribute to teamwork and peer interaction.

Teachers in this study were convinced of the positive contribution of sports activities for students' social development. This is in line with earlier research on social and emotional benefits of sports for adolescents (Bailey 2005; Donaldson and Ronan 2006). However, we have to be careful not to overestimate the beneficial effect of sports, because these effects may mostly occur in sports through positive relationships with peers and adults (Bruner et al. 2011; Holt and Neely 2011) and are highly dependent on a positive and stimulating environment (Hartmann 2003; Hartmann and Kwauk 2011). Moreover, the literature provides also evidence of the opposite, a negative effect of sports on children's social and emotional development (Fraser-Thomas and Côté 2009) for example on self-esteem. Sandford et al. (2006) stated that physical activities are able to re-engage disaffected young people only under the right circumstances. This suggest that sports may beneficially contribute to social development in a curriculum for at-risk students, but that positive peer group climate and good relationships with teachers are necessary for that to occur.

This study was done to investigate how teachers executed a curriculum aimed at at-risk students. Valuable information was provided as to how teachers actually worked with these students and how the teachers sought to help students improve their disengaged, negative behavior. However, students were not participants in this study; according to AlHaqwi et al. (2010), teachers and students may have different perspectives on what an effective curriculum is. Therefore, in order to strengthen determination of key curricular characteristics related to at-risk students, further research should be done with respect to students' perspectives. Teachers in this study felt that, "students know what they want and they see school mostly as an obstacle for reaching their goals". In any case, taking into account both teachers' and students' practical experiences when designing future curricula for this special group of students, seems to be highly commendable.

\section{Abbreviations}

ESL: early school leaver; QUAGOL: qualitative analysis guide of Leuven; RQ: research question; VET: secondary vocational educational institutions.

Authors' contributions

GMF and HTMR did the data collection, analysis and most of the writing. JMP read and corrected the paper and WAJMK read and approved the paper. All authors read and approved the final manuscript.

Author details

${ }^{1}$ Faculty of Behavioral, Management and Social Science, University of Twente, Drienerlolaan 5, 7522 NB Enschede, The Netherlands. ${ }^{2}$ Saxion University of Applied Science, Enschede, The Netherlands. ${ }^{3}$ Faculty of Science, Utrecht University, Utrecht, The Netherlands.

\section{Acknowledgements}

Not applicable.

Competing interests

The authors declare that they have no competing interests.

Availability of data and materials

Data and materials are available on demand. 


\section{Consent for publication}

The authors confirm that the content is not published elsewhere nor submitted for publication. All participants of this study participated on voluntary base and gave permission for anonymous use of data for research publication.

\section{Funding}

Not applicable.

\section{Publisher's Note}

Springer Nature remains neutral with regard to jurisdictional claims in published maps and institutional affiliations.

Received: 28 April 2018 Accepted: 22 December 2018

Published online: 10 January 2019

\section{References}

AlHaqwi Al, van der Molen HT, Schmidt HG, Magzoub ME (2010) Determinants of effective clinical learning: a student and teacher perspective in Saudi Arabia. Educ Health 23(2):1-14

Appleton JJ, Christenson SL, Furlong MJ (2008) Student engagement with school: critical conceptual and methodological issues of the construct. Psychol Schools 45(5):369-386

Bailey R (2005) Evaluating the relationship between physical education, sport and social inclusion. Educ Rev 57(1):71-90 Battistich V, Solomon D, Watson M, Schaps E (1997) Caring school communities. Educ Psychol 32(3):137-151

Blatchford P, Bassett P, Brown P (2011) Examining the effect of class size on classroom engagement and teacherpupil interaction: differences in relation to pupil prior attainment and primary vs. secondary schools. Learn Instr 21(6):715-730

Brekke I (2014) Long term labour market consequences of dropping out of upper secondary school: minority disadvantages? Acta Sociol 57(1):25-39

Bruner MW, Hall J, Côté J (2011) Influence of sport type and interdependence on the developmental experiences of youth male athletes. Eur J Sport Sci 11(2):131-142

Cabus S (2012) An economic perspective on school dropout prevention using micro econometric techniques (doctoral dissertation). University of Maastricht, Maastricht

Cassidy W, Bates A (2005) "Drop-outs" and "push-outs": finding hope at a school that actualizes the ethic of care. Am J Educ 112(1):66-102

Cemalcilar Z, Gökşen F (2014) Inequality in social capital: social capital, social risk and drop-out in the Turkish education system. Br J Sociol Educ 35(1):94-114

De Witte K, Cabus SJ (2013) Dropout prevention measures in the Netherlands, an explorative evaluation. Educ Rev 65(2):155-176

De Witte K, Csillag M (2014) Does anybody notice? On the impact of improved truancy reporting on school dropout. Educ Econ 22(6):549-568

De Witte K, Cabus S, Thyssen G, Groot W, Van den Brink HM (2013) A critical review of the literature on school dropout. Educ Res Rev 10:13-28

Dierckx de Casterlé B, Gastmans C, Bryon E, Denier Y (2012) QUAGOL: a guide for qualitative data analysis. Int J Nurs Stud 49:360-371

Donaldson SJ, Ronan KR (2006) The effects of sports participation on young adolescents'emotional well-being. Adolescence 41(162):369-389

Elffers $L$ (2011) The transition to post-secondary vocational education: students' entrance, experiences, and attainment Doctoral dissertation. IpskampDrukkers: Enschede

Elffers $L$ (2012) Staying on track: behavioral engagement of at-risk and non-at-risk students in post-secondary vocational education. Eur J Psychol Educ 28:545-562

Elffers L, Oort FJ, Karsten S (2012) Making the connection: the role of social and academic school experiences in students' emotional engagement with school in post-secondary vocational education. Learn Individ Differ 22(2):242-250

Fashola OS, Slavin RE (2009) Effective dropout prevention and college attendance programs for students placed at risk. J Educ Stud Placed Risk 3(2):159-183

Finn JD (1989) Withdrawing from school. Rev Educ Res 59(2):117-142

Fraser-Thomas J, Côté J (2009) Understanding adolescents' positive and negative developmental experiences in sport. Sport Psychol 23(1):3-23

Fredricks JA, Blumenfeld PC, Paris AH (2004) School engagement: potential of the concept, state of the evidence. Rev Educ Res 74:59-109

Hartmann D (2003) Theorizing sport as a social intervention: a view from the grassroots. Quest 55(2):118-140

Hartmann D, Kwauk C (2011) Sport and development: an overview, critique and reconstruction. J Sport Soc Issues 35(3):284-305

Hattie, J. (2003). Teachers make a difference, What is the research evidence? Paper presented at the Australian Council for Educational Research Annual Conference on Building Teacher Quality, Melbourne Australia

Holt NL, Neely KC (2011) Positive youth development through sport: a review. Revista Iberoamericana De Psicología Del Ejercicio y El Deporte 6:299-316

Hoxby CM (2000) The effects of class size on student achievement: new evidence from population variation. Q J Econ 115(4):1239-1285

Keller JM (2010) Motivational design for learning and performance: the ARCS model approach. Springer, New York

Lamb S, Markussen E, Teese R, Sandberg N, Polesel J (2011) School dropout and completion. International comparative studies in theory and policy. Springer, New York 
Lee VE, Burkham DT (2003) Dropping out of high school: the role of school organization and structure. Am Educ Res J 40(2):353-393

Markussen E, Frøseth MW, Sandberg N (2011) Reaching for the unreachable: identifying factors predicting early school leaving and non-completion in Norwegian upper secondary education. Scand J Educ Res 55(3):225-253

Martin AJ, Dowson M (2009) Interpersonal relationships, motivation, engagement, and achievement: yields for theory, current issues, and educational practice. Rev Educ Res 79(1):327-365

Ministry of Education, Culture and Science (2017) Kamerbrief bekendmaking nieuwe ciffers voortijdig schoolverlaten. [Letter to parliament publishing new number for early school leaving]. https://www.rijksoverheid.nl/onderwerpen/ vsv/documenten/kamerstukken/2017/02/21/kamerbrief-bekendmaking-nieuwe-cijfers-voortijdig-schoolverlaten

Montgomery GT, Hirth MA (2011) Freshman transition for at-risk students. NASSP Bull 95(4):245-265

Newberry M (2010) Identified phases in the building and maintaining of positive teacher-student relationships. Teach Teach Educ 26(8):1695-1703

Oreopoulos P (2007) Do dropouts drop out too soon? Wealth, health and happiness from compulsory schooling. J Public Econ 91:2213-2229

Pyle N, Wexler J (2012) Preventing students with disabilities from dropping out. Interv School Clin 47(5):283-289

Rumberger RW (1995) Dropping out of middle school: a multilevel analysis of students and schools. Am Educ Res J 32(3):583-625

Rumberger RW (2001) Why students drop out of school and what can be done. In: Paper prepared for the conference, Dropouts in America: How severe is the problem? What do we know about intervention and prevention? Cambridge: Harvard University

Ryan AM (2000) Peer groups as a context for the socialization of adolescents' motivation, engagement, and achievement in school. Educ Psychol 35(2):101-111

Ryan RM, Deci EL (2000) Self-determination theory and the facilitation of intrinsic motivation, social development and well-being. Am Psychol 55(1):68-78

Ryan AM, Patrick H (2001) The classroom social environment and changes in adolescents' motivation and engagement during middle school. Am Educ Res J 38(2):437-460

Sanders WL, Wright SP, Horn SP (1997) Teacher and classroom context effects on student achievement: implications for teacher evaluation. J Pers Eval Educ 11(1):57-67

Sandford RA, Armour KM, Warmington P (2006) Re-engaging disaffected youth through physical activity programmes. Br Edu Res J 32(2):2251-2271

Schuchart C (2013) School social capital and secondary education plans. Educ Stud 39(1):29-42

Sharp C, Chamberlain T, Morrison J, Filmer-Sankey C (2007) Playing for success and its long term impact. Research report. Department for Education and Skills, United Kingdom

Slavin RE (1989) Class size and student achievement: small effects of small classes. Educ Psychol 24(1):99-110

Smith ML, Glass GV (1980) Meta-analysis of research on class size and its relationship to attitudes and instruction. Am Educ Res J 17(4):419-433

Thijs A, Van den Akker J (2009) Curriculum in development. Stichting Leerplan Onderwijs, Enschede

Timperley H, Alton-Lee A (2008) Reframing teacher professional learning: an alternative policy approach to strengthening valued outcomes for diverse learners. Rev Res Educ 32(1):328-369

Van den Akker J (2003) Curriculum perspectives: an introduction. In: van den Akker J, Kuiper W, Hameyer U (eds) Curriculum landscapes and trends. Kluwer Academic Publisher, Dordrecht, pp 1-10

Van der Steeg M, Van Elk R, Webbink D (2012) Does intensive coaching reduce school dropout? Evidence from a randomized experiment. [Discussion Paper 224]. Den Haag: Cultureel Plan Bureau

Van Houtte M, Demanet J (2016) Teachers' beliefs about students, and the intention of students to drop out of secondary education in Flanders. Teach Teach Educ 54:117-127

Van Uden J, Ritzen H, Pieters J (2013) I think I can engage my students. Teachers' perceptions of student engagement and their beliefs about being a teacher. Teach Teach Educ 32:43-54

Waldrip B, Cox P, Deed G, Dorman J, Edwards D, Farrelly C, Yager Z (2014) Student perceptions of personalised learning: development and validation of a questionnaire with regional secondary students. Learn Environ Res 17:355-370

Webbink D, Koning P, Vujic S, Martin NG (2012) Why are criminals less educated than non-criminals? Evidence from a cohort of young Australian twins. J Law Econ Organ 29:115-124. https://doi.org/10.1093/jleo/ews014

Wentzel KR, Wigfield A (2007) Motivational interventions that work: themes and remaining issues. Educ Psychol 42(4):261-271 